\title{
Physiological and Biochemical Responses of Jerusalem Artichoke Seedlings to Mixed Salt-Alkali Stress Conditions
}

\author{
Shuai SHAO, Mingming QI, Shuang TAO, Jixiang LIN, Yingnan WANG, Xiufeng YAN* \\ Alkali Soil Natural Environmental Science Center, Northeast Forestry University/Key Laboratory of Saline-alkali Vegetation Ecology Restoration in Oil Field, \\ Ministry of Education, 150040Harbin,China; xfyan@nefu.edu.cn ("correspondingauthor)
}

\begin{abstract}
Soil salinization and alkalization frequently co-occur in the grassland, but little information exists concerning the mixed effects of salt-alkaline stress on plant. Jerusalem artichoke is an economically and ecologically important energy crop and also considered as a salt-tolerant species. In this study, we investigated the effects of 12 mixed salt-alkaline conditions on the seedling growth and responses of Jerusalem artichoke to such conditions. The results showed that the seedling growth decreased with the increasing salinity and $\mathrm{pH}$, and the destructive effects were more markedly under the interactions of highest salinity and $\mathrm{pH}$. The $\mathrm{Na}^{+}, \mathrm{Mg}^{2+}$ and $\mathrm{Ca}^{2+}$ concentrations were all increased with the increasing salinity and $\mathrm{pH}$, but the $\mathrm{K}^{+}$ kept stable. The $\mathrm{Cl}^{-}$concentration increased when the treatment without alkali salts, and the $\mathrm{NO}_{3}{ }^{-}$and $\mathrm{H}_{2} \mathrm{PO}_{4}{ }^{-}$concentrations were decreased with the increasing salinity. Jerusalem artichoke seedlings enhanced organic acids and proline to supply the shortage of inorganic anions and cope with osmotic stress from the high $\mathrm{Na}^{+}$concentration. Above results show that the toxicity effects of the interactions of salt stress and alkali stress on plant is much greater than that only salt or alkali stress. A better understanding of the seedlings of Jerusalem artichoke under mixed salt-alkali stress conditions should facilitate the effective utilization of this species under such complex environment in Northeast China.
\end{abstract}

Keywords: Jerusalem artichoke, mixed salt-alkali stress, physiological changes, organic acids

\section{Introduction}

Jerusalem artichoke (Helianthus tuberosus L.) is a tuberous plant belongs to the sunflower family. It was introduced into Europe in the late 1500s from North America, and then cultivated across Europe and Asia over the centuries, both for human consumption and as a feed for grazing livestock (Baldini et al., 2004). Currently, Jerusalem artichoke is cultivated for many application areas such as source of sugars, green forage, crude material for production of ethanol, and pharmaceuticals applications (Baldini et al., 2004; Saengthongpinit and Sajjaanantakul, 2005). In addition, it grows very rapidly and can reach a height of $2-4 \mathrm{~m}$. It is also has highly tolerant to salt soil due to the deep root system (Zhao et al., 2008). In conclusion, Jerusalem artichoke is an economically and ecologically important energy crop species for humans.

Soil salinization and alkalization is an important environmental problem all over the world, especially in China. Salinity-alkalinity soil decreases the plant growth and production and also lead to large area of land degradation. For example, arable land acreage of the world is $1.5 \times 10^{9}$ ha, but $23 \%$ $\left(0.34 \times 10^{9} \mathrm{ha}\right)$ of the area is saline, and $37 \%\left(0.56 \times 10^{9} \mathrm{ha}\right)$ is sodic (Tanji, 1990; Lin et al., 2014). In the Northeast of China, almost $70 \%$ of the grassland has been serious degraded due to salt-alkali soil, and the area is expanding all the time (Deng et al., 2006).

In addition, soil salinization and alkalization are co-occur, and the stress effect on the plant is always much greater than that only salt or alkali stress. Previous studies have been proved that salt stress and alkali stress are great differed due to the high $\mathrm{pH}$, and the alkali stress is more severe than salt stress (Shi and Yin, 1993; Guo et al., 2009; Zhang and Mu, 2009). Under salt stress, plants always maintain high $\mathrm{K}^{+}$and $\mathrm{Ca}^{2+}$ levels and exclude $\mathrm{Na}^{+}$ from the shoots, synthesize many organic solutes such as proline in the cytoplasm to resist the osmotic stress, and also accumulate inorganic ions such as $\mathrm{Cl}^{-}$in order to keep ion balance (Kerepesi and Galiba, 2000; Ashraf et al., 2007). While under alkali stress, accumulation of organic acids is the main way to resist the high $\mathrm{pH}$ stress. However, the conditions of plant surviving in the saltalkali soil are very complex, contain both the salt and alkali stresses (Shi and Yin, 1993; Shi and Wang, 2005; Li et al., 2010). Thus, the effect of mixed salt-alkali stress should be distinguished from salt stress or alkali stress, and the physiological and biochemical responses to such conditions maybe also unique.

There are a few reports on the effects of mixed salt-alkali stress on plant seedlings (Shi and Wang, 2005; Peng et al., 2008; Yang et al., 2011), and also some reports on seed germination (Li et al., 2010; Lin et al., 2014). However, most 
474

Table 1. Salt composition and molar ratio of various treatments

\begin{tabular}{ccccc}
\hline \multirow{2}{*}{ Treatments } & \multicolumn{4}{c}{ Salt composition and molar proportions } \\
\cline { 2 - 5 } & $\mathrm{NaCl}$ & $\mathrm{Na}_{2} \mathrm{SO}_{4}$ & $\mathrm{NaHCO}_{3}$ & $\mathrm{Na}_{2} \mathrm{CO}_{3}$ \\
\hline $\mathrm{A}$ & 1 & 1 & 0 & 0 \\
$\mathrm{~B}$ & 1 & 2 & 1 & 0 \\
$\mathrm{C}$ & 1 & 1 & 1 & 1 \\
$\mathrm{D}$ & 9 & 1 & 1 & 9 \\
\hline
\end{tabular}

Table2. Stress factors of various treatments

\begin{tabular}{|c|c|c|c|c|c|c|c|}
\hline \multirow{2}{*}{ Treatment } & \multicolumn{7}{|c|}{ Stress factors } \\
\hline & $\mathrm{pH}$ & Salinity/mM & $\mathrm{Na}+/ \mathrm{mM}$ & $\mathrm{Cl}-/ \mathrm{mM}$ & SO42-/mM & $\mathrm{HCO} 3-/ \mathrm{mM}$ & $\mathrm{CO} 32-/ \mathrm{mM}$ \\
\hline A0 & 7.02 & 0 & 0 & 0 & 0 & 0 & 0 \\
\hline A1 & 7.13 & 20 & 30 & 10 & 10 & 0 & 0 \\
\hline A2 & 7.14 & 40 & 60 & 20 & 20 & 0 & 0 \\
\hline A3 & 7.22 & 60 & 90 & 30 & 30 & 0 & 0 \\
\hline B0 & 7.02 & 0 & 0 & 0 & 0 & 0 & 0 \\
\hline B1 & 7.95 & 20 & 30 & 5 & 10 & 5 & 0 \\
\hline B2 & 8.05 & 40 & 60 & 10 & 20 & 10 & 0 \\
\hline B3 & 8.10 & 60 & 90 & 15 & 30 & 15 & 0 \\
\hline $\mathrm{C} 0$ & 7.02 & 0 & 0 & 0 & 0 & 0 & 0 \\
\hline $\mathrm{C} 1$ & 9.32 & 20 & 30 & 5 & 5 & 5 & 5 \\
\hline $\mathrm{C} 2$ & 9.42 & 40 & 60 & 10 & 10 & 10 & 10 \\
\hline C3 & 9.49 & 60 & 90 & 15 & 15 & 15 & 15 \\
\hline D0 & 7.02 & 0 & 0 & 0 & 0 & 0 & 0 \\
\hline D1 & 10.05 & 20 & 30 & 9 & 1 & 1 & 9 \\
\hline D2 & 10.09 & 40 & 60 & 18 & 2 & 2 & 18 \\
\hline D3 & 10.18 & 60 & 90 & 27 & 3 & 3 & 27 \\
\hline
\end{tabular}

studies described how the plant changed under such condition. To our knowledge, the physiological adaptation mechanism of plant seedlings especially the Jerusalem artichoke is still unclear. A better understanding of the seedlings of Jerusalem artichoke under mixed salt-alkali stress conditions should facilitate the effective utilization of this species under such complex environment in the Northeast of China.

In this study, mixtures of two neutral salts $(\mathrm{NaCl}$ and $\left.\mathrm{Na}_{2} \mathrm{SO}_{4}\right)$, two alkaline salts $\left(\mathrm{NaHCO}_{3}\right.$ and $\mathrm{Na}_{2} \mathrm{CO}_{3}$ ) were used in different proportions to simulate 12 treatments of mixed saltalkaline conditions. The aims were (1) to test the effects of mixed salt-alkali stresses on the seedling growth of Jerusalem artichoke, (2) to explore the physiological adaptation mechanism of Jerusalem artichoke under such conditions.

\section{Materials and Methods}

\section{Design of the mixed salt-alkali stress conditions}

In order to simulate the mixed salt-alkali conditions, $\mathrm{NaCl}$, $\mathrm{Na}_{2} \mathrm{SO}_{4}, \mathrm{NaHCO}_{3}$ and $\mathrm{Na}_{2} \mathrm{CO}_{3}$ were chose based on the salt composition of the salt-alkali soil in the Northeast of China (Peng et al., 2008). Four salts were mixed in different proportions according to the salinity and $\mathrm{pH}$ in the Songnen grassland. Four treatment groups (A-D) were set with the increasing alkalinity. Salt composition and molar ratio of various treatments are shown in Table 1. Within each group, three concentrations were used $(20,40$ and $60 \mathrm{mM})$. Total 12 mixed stress treatments $\left(A_{1}\right.$ $\mathrm{D}_{5}, \mathrm{pH} 7.02-10.18$, and salinity 20-60 mM) are shown in Table 2.

\section{Plantmaterial}

Experiments were conducted in Northeast Forestry University (126 $38^{\circ} \mathrm{E}, 45^{\circ} 45^{\prime} \mathrm{N}$, Harbin, China) during May and June. Jerusalem artichoke (Helianthus tuberosus L.) tubers were sown in 15-cm-diameter plastic pots filled with $2.5 \mathrm{~kg}$ washed sand. Each pot was taken as a single replicate, and contained three tubers and watered until emergence. All the plants were irrigated with Hoagland nutrient solution once a day from emergence to $40 \mathrm{~d}$ after sowing. The Hoagland nutrition solution in our research contained $5.00 \mathrm{mM} \mathrm{Ca}^{2+}, 2.00 \mathrm{mM} \mathrm{Mg}^{2+}, 6.04 \mathrm{mM} \mathrm{K}^{+}$, $22.2 \mu \mathrm{M}$ EDTA-Fe $\mathrm{Fe}^{2+}, 6.72 \mu \mathrm{M} \mathrm{Mn}^{2+}, 3.16 \mu \mathrm{M} \mathrm{Cu}^{2+}, 0.765 \mu \mathrm{M}$ $\mathrm{Zn}^{2+}, 2.10 \mathrm{mM} \mathrm{SO}_{4}^{2-}, 1.00 \mathrm{mM} \mathrm{H}_{2} \mathrm{PO}_{4}^{-}, 46.3 \mu \mathrm{M} \mathrm{H}_{3} \mathrm{BO}_{3}$, $0.556 \mu \mathrm{M} \mathrm{H}_{2} \mathrm{MoO}_{4}$, and $15.04 \mathrm{mM} \mathrm{NO}_{3}^{-}$(Lin et al., 2014). Plants were cultivated in a greenhouse with natural light.

\section{Stress treatment andseedling harvest}

The Jerusalem artichoke seedlings were subjected to stress treatments after $40 \mathrm{~d}$, and 52 pots with uniform seedlings were divided randomly into 13 sets, four pots per set. Each set contained four replicates. The pots were watered daily with nutrient solution containing the appropriate stress salts as above stated. The control seedlings were watered with only the nutrient solution. The total treatment duration was $8 \mathrm{~d}$. Harvest seedlings were washed with distilled water twice, and then the shoots were retained, the fresh weight was determined for each plant. The shoots were oven-dried at $80^{\circ} \mathrm{C}$ for $15 \mathrm{~min}$ and then at $65^{\circ} \mathrm{C}$ to a constant weight. The water content (WC) was calculated using the formula (FWDW)/DW. FW is short for fresh weight, DW is short for dry weight.

\section{Determination of inorganicions and organic solutes}

Dry samples of plant material $(50 \mathrm{mg})$ were treated with $10 \mathrm{~mL}$ deionized water at $100{ }^{\circ} \mathrm{C}$ for $1 \mathrm{~h}$ and the extract was taken to determine free inorganic ions, organic acids. An atomic absorption spectrophotometer (TAS-990, Purkinje General, Beijing) was used to determine the $\mathrm{Na}^{+}, \mathrm{K}^{+}, \mathrm{Mg}^{2+}$ and $\mathrm{Ca}^{2+}$ contents. The $\mathrm{NO}_{3}, \mathrm{Cl}$ and $\mathrm{H}_{2} \mathrm{PO}_{4}$ contents were determined by ion chromatography (DX-300 ion chromatographic system, USA), and the 
Table 3. Two-way ANOVA of effects of salinity, $\mathrm{pH}$ and their interactions on the growth and physiological index of Jerusalem artichoke

\begin{tabular}{|c|c|c|c|c|}
\hline Index & Item & Group & Salinity & Group $\times$ Salinity \\
\hline Fresh weight & F-ratio ${ }^{P}$ & $74.93^{* * *}$ & $146.33^{* * *}$ & $0.63^{\text {ns }}$ \\
\hline Dry weigh & F-ratio ${ }^{P}$ & $124.0^{* * *}$ & $81.1^{* * *}$ & $0.8^{\text {ns }}$ \\
\hline Water content & F-ratio ${ }^{P}$ & $65.1^{* * *}$ & $248.4^{* * *}$ & $14.5^{* * *}$ \\
\hline $\mathrm{Na}^{+}$content & F-ratio ${ }^{P}$ & $259.0^{* * *}$ & $1038.8^{* * *}$ & $33.98^{* * *}$ \\
\hline $\mathrm{K}^{+}$content & F-ratio ${ }^{P}$ & $2.5^{\mathrm{ns}}$ & $0.7^{\mathrm{ns}}$ & $6.8^{* * *}$ \\
\hline $\mathrm{Ca}^{2+}$ content & F-ratio ${ }^{P}$ & $125.7^{* * *}$ & $495.5^{* * *}$ & $14.8^{* * *}$ \\
\hline $\mathrm{Mg}^{2+}$ content & F-ratio ${ }^{P}$ & $252.5^{* * *}$ & $1027.6^{* * *}$ & $28.7^{* * *}$ \\
\hline $\mathrm{Cl}^{-}$content & F-ratio ${ }^{P}$ & $190.4^{* * *}$ & $43.7^{* * *}$ & $19.0^{* * *}$ \\
\hline $\mathrm{NO}_{3}{ }^{-}$content & F-ratio ${ }^{P}$ & $211.4^{* * *}$ & $79.9^{* * *}$ & $2.5^{*}$ \\
\hline $\mathrm{H}_{2} \mathrm{PO}_{4}^{-}$content & F-ratio ${ }^{P}$ & $111.0^{* * *}$ & $1099.6^{* * *}$ & $13.3^{* * *}$ \\
\hline Citrate acid & F-ratio $^{P}$ & $176.5^{* * *}$ & $899.2^{* * *}$ & $28.5^{* * *}$ \\
\hline Oxalate acid & F-ratio ${ }^{P}$ & $192.3^{* * *}$ & $764.1^{* * *}$ & $32.6^{* * *}$ \\
\hline Maliate acid & F-ratio ${ }^{P}$ & $215.8^{* * *}$ & $785.5^{* * *}$ & $40.4^{* * *}$ \\
\hline Proline & F-ratio ${ }^{P}$ & $1351.0^{* * *}$ & $1116.8^{* * *}$ & $530.4^{* * *}$ \\
\hline
\end{tabular}
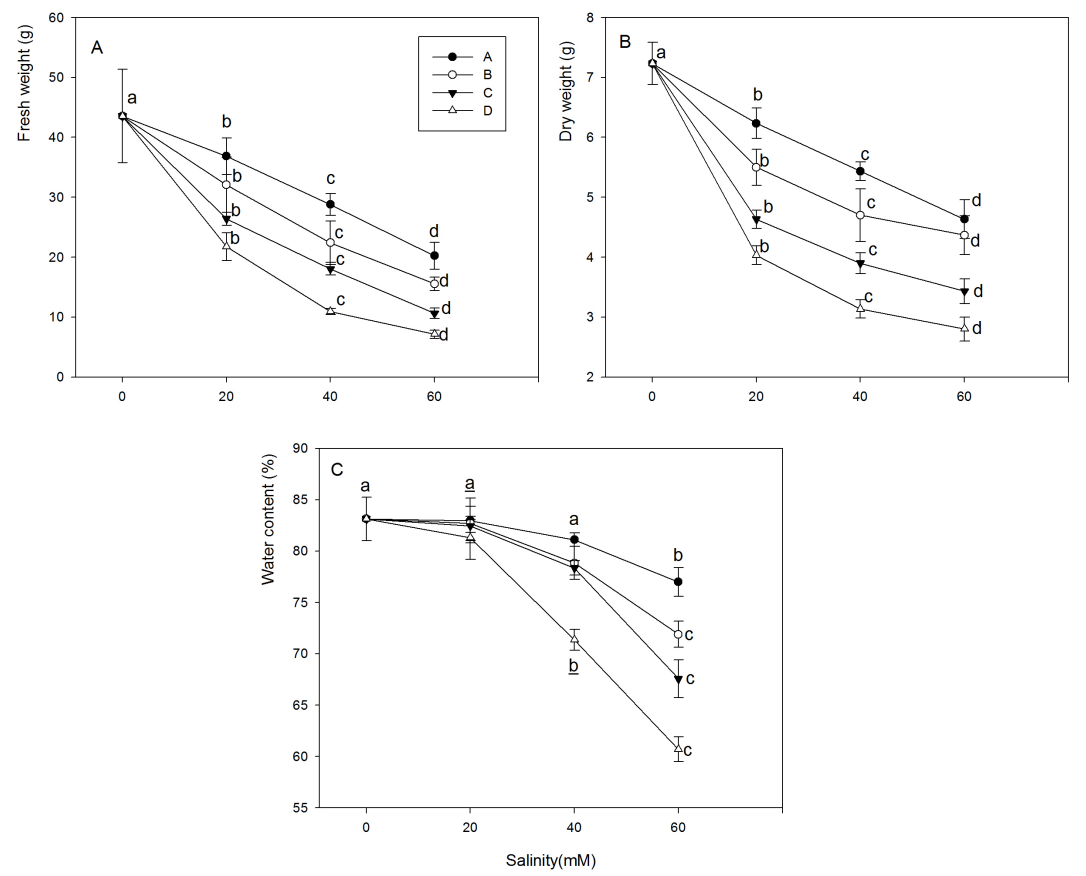

Fig. 1.Effects of mixed salt-alkaline stresses on fresh weight (A), dry weight (B) and water content (C) of Jerusalem artichoke

The values are the means of four replicates. Means followed by different letters are significantly different at $\mathrm{P}<0.05$ according to a least significant difference test

measurement conditions were as follows: AS4A-SCion exchange column, CD M-II electric conductivity detector, mobile phase was $\mathrm{Na}_{2} \mathrm{CO}_{3} / \mathrm{NaHCO}_{3}=1.7 / 1.8 \mathrm{mM}$. For the analysis of organic acids, the measurements were also undertaken using ion chromatography (DX-300 ion chromatographic system, USA), and the measurement conditions were as follows: ICE-AS6 analytical column, CDM-II electric conductivity detector, AMMS-ICE II interference suppressor, mobile phase was $0.4 \mathrm{mM}$ perfluorobutyric acid, flow speed was $1.0 \mathrm{~mL} / \mathrm{min}$, column temperature was $20^{\circ} \mathrm{C}$, sample size was $50 \mu \mathrm{L}$. The content of proline was measured using ninhydrin, according to Zhu et al. (1983).

Data analysis

All data were analyzed using SPSS 13.0. Tukey's tests were performed for multiple comparisons to determine significant $(P<0.05)$ differences between individual treatments. A two-way
ANOVA was used to test the effects of the factors ( $\mathrm{pH}$ and salinity) and their interactions on seedling growth and physiological change index. The data were expressed as mean \pm S.E.

\section{Results}

Effects on the seedlinggrowth and water content

The fresh and dry weights of Jerusalem artichoke seedlings were significantly affected by $\mathrm{pH}$ and salinity $(P<0.001$, Table 3$)$, but not significantly by the interaction of the two factors. Maximum seedling weight (fresh and dry) were obtained both in the distilled water, which were $43.6 \mathrm{~g}$ and $7.2 \mathrm{~g}$, respectively. Seedling weight decreased with the increasing salinity in all the treatment groups, and more markedly in group D (Fig.1). At the highest salinity $(60 \mathrm{mM})$, the dry weight in group A was $4.6 \mathrm{~g}$, while $4.3 \mathrm{~g}, 3.4 \mathrm{~g}$ and $2.8 \mathrm{~g}$ in the other 3 groups, respectively. 
476

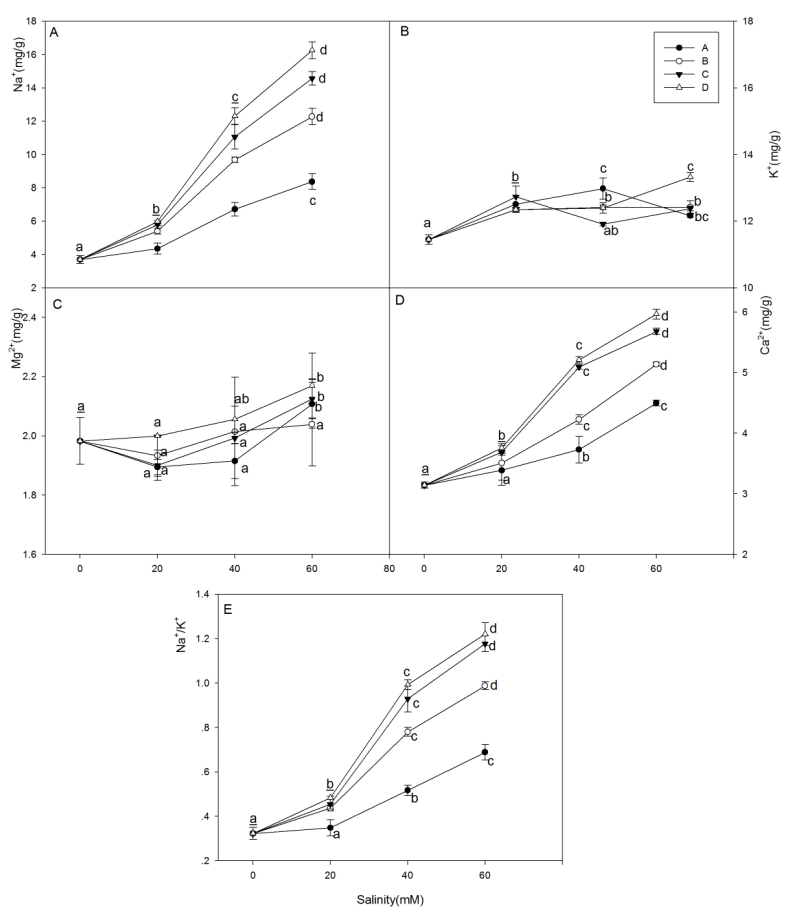

Fig. 2. Effects of mixed salt-alkaline stresses on $\mathrm{Na}^{+}$content $(\mathrm{A}), \mathrm{K}^{+}$ content (B), $\mathrm{Mg}^{2+}$ content $(\mathrm{C}) \mathrm{Ca}^{2+}$ content $(\mathrm{D})$ and $\mathrm{Na}^{+} / \mathrm{K}^{+}(\mathrm{E})$ of Jerusalem artichoke

The values are the means of four replicates. Means followed by different letters are significantly different at $\mathrm{P}<0.05$ according to a least significant difference test

Water content in the shoot was significantly affected by $\mathrm{pH}$, salinity and the interaction of the two factors $(P<0.001$, Table 3$)$. Maximum water content was also obtained in distilled water. In group A, the water content significantly decreased only when the salinity reached $60 \mathrm{mM}$. In group $\mathrm{D}$, when the salinity reached highest $(60 \mathrm{mM})$, the water content decreased of $25 \%$ compared to the control (Fig. 1).

\section{Effects on inorganicions contents}

The $\mathrm{Na}^{+}, \mathrm{Mg}^{2+}$ and $\mathrm{Ca}^{2+}$ contents were significantly affected by the $\mathrm{pH}$, salinity and the interaction of the two factors $(P<0.001$, Table 3). However, the $\mathrm{K}^{+}$content was not significantly affected. Within each group, the $\mathrm{Na}^{+}$contents were increased with the increasing salinity, and reached the highest value at $60 \mathrm{mM}$. In addition, the ratio of the alkali salts were also affected the $\mathrm{Na}^{+}$ content. The $\mathrm{Na}^{+}$content in group D is $16.3 \mathrm{mg} / \mathrm{g}$ but only 8.4 $\mathrm{mg} / \mathrm{g}$ in the group A at $60 \mathrm{mM}$ salinity (Fig. $2 \mathrm{~A}$ ).

The $\mathrm{K}^{+}$content changed unregularity in all the treatments, but compared with the control, the $\mathrm{K}^{+}$content did not change significantly (Fig.2B). In addition, due to the $\mathrm{Na}^{+}$content increased sharply with the increasing alkali salts, the $\mathrm{Na}^{+} / \mathrm{K}^{+}$had the similar change trends with the $\mathrm{Na}^{+}$content. The maximum value (1.2) was appeared at $60 \mathrm{mM}$ in the group D (Fig. 2E). In addition, the $\mathrm{Mg}^{2+}$ and $\mathrm{Ca}^{2+}$ contents were also showed a increasing trends with the increasing salinity and the ratio of alkali salts. The maximum values were both appeared at $60 \mathrm{mM}$ in the group D (Fig. 2CD).

The $\mathrm{NO}_{3}, \mathrm{Cl}^{-}$and $\mathrm{H}_{2} \mathrm{PO}_{4}$ contents were all significantly affected by the $\mathrm{pH}$, salinity and the interaction of the two factors $(P<0.001$, Table 3$)$. The $\mathrm{Cl}^{\prime}$ content significantly increased with

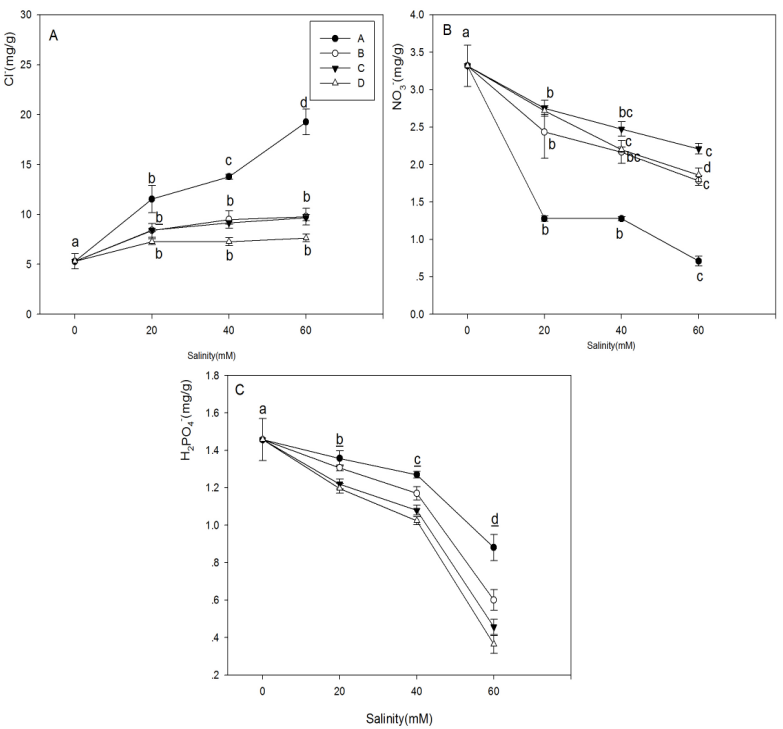

Fig. 3. Effects of mixed salt-alkaline stresses on $\mathrm{Cl}$ content (A), $\mathrm{NO}_{3}$ content $(\mathrm{B})$ and $\mathrm{H}_{2} \mathrm{PO}_{4}(\mathrm{C})$ of Jerusalem artichoke

The values are the means of four replicates. Means followed by different letters are significantly different at $\mathrm{P}<0.05$ according to a least significant difference test

the increasing salinity at A group $(P<0.05)$, and was 3.7 times than that in the control group at the highest salinity. However, the $\mathrm{Cl}^{-}$ content significantly increased when the salinity reached $20 \mathrm{mM}$, and kept unchanged when the salinity was much higher. The changing trends were similar between $\mathrm{NO}_{3}^{-}$and $\mathrm{H}_{2} \mathrm{PO}_{4}^{-}$contents, both of the values were decreased with the increasing salinity and reached the lowest at $60 \mathrm{mM}$ salinity in the final (Fig. 3).

\section{Effects on organic solutes contents}

Maliate acid, citric acid and oxalate acid were detected in the shoot of Jerusalem artichoke under mixed salt-alkali stress conditions. The three organic acids were significantly affected by the $\mathrm{pH}$, salinity and the interaction of the two factors $(P<0.001$, Table 3). In addition, the three organic acids had the similar change trends in each stress group, they were all increased when the alkali salt ratio was higher. There was no significant difference in the maliate acid and citric acid contents compared with the control in group A except oxalate acid. At the highest salinity stress, the organic acids contents were 1.8 times, 3.6 times and 2.2 times than that of the control, respectively (Fig.4).

The proline content was significantly affected by the $\mathrm{pH}$, salinity and the interaction of the two factors $(P<0.001$, Table 3$)$. Although the proline content increased with the salinity in the group $A$ and $\mathrm{B}$, the rangeability was not large. However, in the group D, when the salinity reached $60 \mathrm{mM}$, the proline content was 13.5 times than that of the control (Fig. 5).

\section{Discussion}

In this study, the 12 treatments covered various salt-alkali stress conditions in a range of $\mathrm{pH}$ from 7.02 to 10.18 , which is approximate to the Songnen grassland in the Northeast of China. In the salt-alkali soil of Northern China, the stress factors are very difficult to simulate. However, the mixed stress treatments used in our research made the reasearch of complex natural environment conditions possible. Most privious studies 


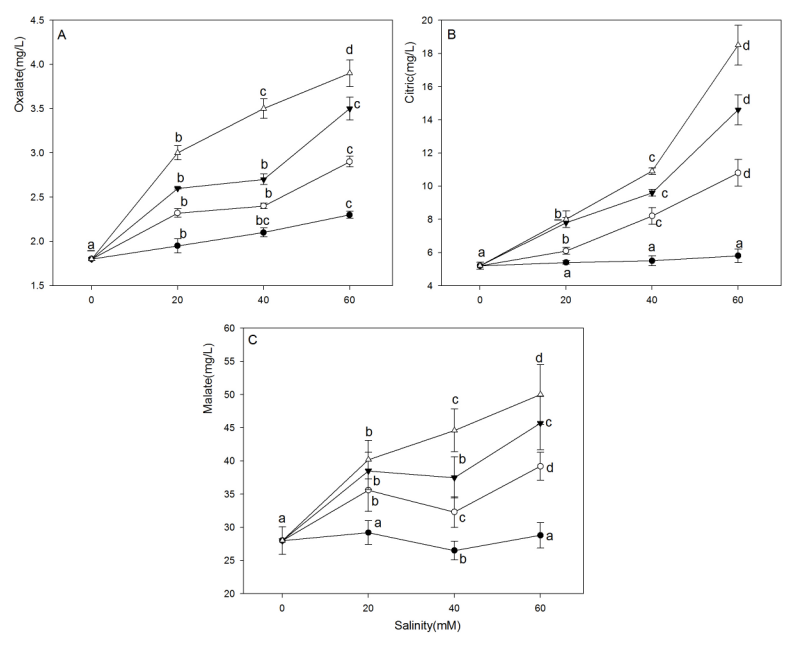

Fig. 4. Effects of mixed salt-alkaline stresses on oxalate acid content (A), citric acid (B) and maliate acid (C) of Jerusalem artichoke

The values are the means of four replicates. Means followed by different letters are significantly different at $\mathrm{P}<0.05$ according to a least significant difference test

only concerned salt stress of alkali stress (Munns, 2002; Debez et al., 2004; Ashraf and Foolad, 2007; Yang et al., 2007, 2009, 2010). However, little information exsit concerning the mixed salt-alkali stress conditions.

Seedling establishment is the most important stage for plant surviving in the salt-alkali conditions. This stage is also very sensitive to salinity and alkalinity in the soil. Understanding the physiological responses of Jerusalem artichoke to mixed salt-alkali stress conditions during seedling stage has an important exploring significance. Our results showed that the more ratio of the alkali salts in the treatment, the lower of the fresh weight and dry weight. This indicated that the high $\mathrm{pH}$ played important roles in seedling growth, especially at higher salt concentration. The negative effects of salt stress on the plant are mainly contains osmotic stress and toxic ion, but the allkali stress exerts the high $\mathrm{pH}$ impacts. Once the salt stress and alkali stress are mixed, the destructive effects on the plant is much greater due to the mixed effects of salinity, $\mathrm{pH}$ and toxic ions. Losing water is also a quick way to osmotic adjustment in response to the osmotic stress for most plants (Lissner et al., 1999). With the increasing salt stress, the water content in the shoots of Jerusalem artichoke were decreased. The reasons maybe that the root was damaged under stress condions and then the ability of water absorption was decreased. In addition, many organic solutes were synthesis under such conditons and the water content in the shoots were reduced.

In general, the $\mathrm{Na}^{+}$entered the plant cells through the highaffinity $\mathrm{K}^{+}$transporter (HKT) and non-selective cation channels (Zhu, 2003). Most plants in the salt environment accumulated a large number of $\mathrm{Na}^{+}$and simultaneously inhibited the $\mathrm{K}^{+}$ absorption (Munns, 2002). In this research, although the $\mathrm{Na}^{+}$ concentration increased, the $\mathrm{K}^{+}$concentration was not affected. Similar results were also found in some other halophytes in Songnen grassland in China, such as Kochia sieversiana and Suaeda glauca (Yang et al., 2007, 2008). This showed that the increased $\mathrm{Na}^{+}$concentrations did not induce the decreased $\mathrm{K}^{+}$ concentrations in shoot of Jerusalem artichoke, indicating that a specific ion transport mechanism may exit between $\mathrm{Na}^{+}$and $\mathrm{K}^{+}$

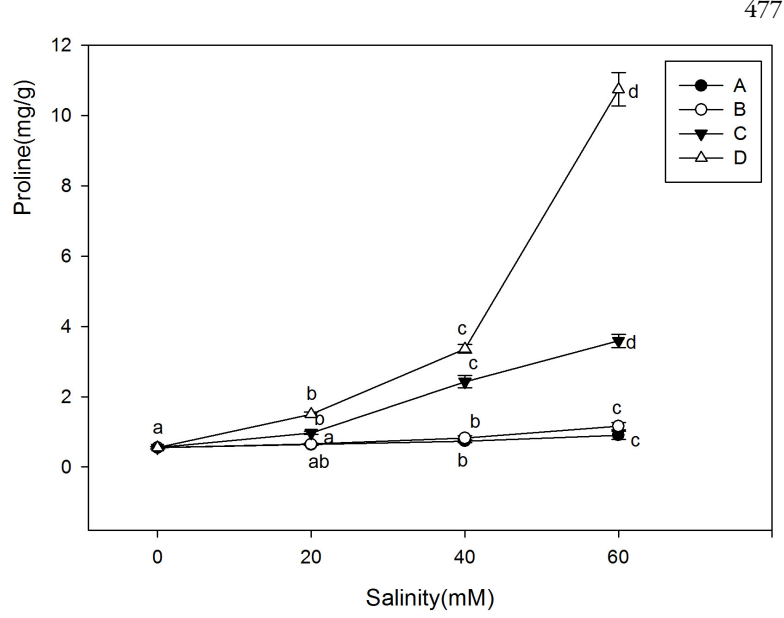

Fig. 5. Effects of mixed salt-alkaline stresses on proline content of Jerusalem artichoke

The values are the means of four replicates. Means followed by different letters are significantly different at $\mathrm{P}<0.05$ according to a least significant difference test

absorptions in this species. However, due to the great number of the $\mathrm{Na}^{+}$, the $\mathrm{Na}^{+} / \mathrm{K}^{+}$increased sharply at higher salinity in group D. High $\mathrm{Na}^{+} / \mathrm{K}^{+}$ratio can affect ions regionalization, lead to ions imbalance, and also reduce enzyme activities. This is why the fresh and dry weights were lowest in this treatment.

Under the circumstance of higher $\mathrm{Na}^{+}$concentration, most plants accumulate the inorganic anions, such as $\mathrm{Cl}^{-}$and $\mathrm{NO}_{3}{ }^{-}$in order to keep the ionic balance. In our study, when the treatment was without alkali salts, Jerusalem artichoke accumulated much $\mathrm{Cl}^{-}$to balance the influx of $\mathrm{Na}^{+}$(Fig. 3A). However, once the treatment contained the alkali salts, all the anion contents decreased, indicating that high $\mathrm{pH}$ inhibited absorptions of $\mathrm{Cl}$. Similar results were also reported for other plants, like Chloris virgata (Yang et al., 2010). Seedlings accumulated much organic acids to compensate the anions deficit caused by high $\mathrm{pH}$. Accumulation of organic acids not only played an important osmotic role but also buffered excess toxic cations and kept ionic balance, such as maliate acid, citric acid and oxalate acid in this species. Although a great number of inorganic ions accumulate in vacuoles, plants can also synthesize low molecular mass organic solutes in the cytoplasm, such as proline to prevent dehydration and protect biomacromolecules (Parida and Das, 2005, Long et al., 2010). In the present study, proline was accumulated under stress conditions, especially at higher salinity in group D, indicating that changes of proline content in seedlings may be a special physiological response to high intensity $\mathrm{pH}$ stress.

\section{Acknowledgements}

The research was supported by the National Natural Science Foundation of China $(31470467,31502013)$ and the Natural Science Foundation of Heilongiang Province (C2015060).

\section{References}

Ashraf M, Foolad MR (2007). Roles of glycine betaine and proline in improving plant abiotic stress resistance. Environmental and Experimental Botany 59:206-216. 
478

Baldini M, Danuso F, Turi M, Vannozzi, GP (2004). Evaluation of new clones of Jerusalem artichoke (Helianthus tuberosus L.) for inulin and sugar yield from stalks and tubers. Industrial Crops and Products 19:25-40.

Debez A, Hamed BK, Grignon C, Abdelly C (2004). Salinity effects on germination, growth, and seed production of the halophyte Cakile maritime. Plant and Soil 262:179-189.

Deng W, Qiu SW, Liang ZW (2006). Regional Eco-environment Background of the China Da'an Sodic Land Experiment Station. Beijing, Science Press.

Guo R, Shi LX, Yang YF (2009). Germination, growth, osmotic adjustment and ionic balance of wheat in response to saline and alkaline stresses. Soil Science and Plant Nutrition 55:667-679.

Kerepesi I, Galiba, G (2000). Osmotic and salt stress-induced alteration in soluble carbohydrate content in wheat seedlings. Crop Science 40: $482-487$.

Li R, Shi F, Fukuda K (2010). Interactive effects of salt and alkali stresses on seed germination, germination recovery, and seedling growth of a halophyte Spartina alterniflora (Poaceae). South African Journal of Botany 76:380-387.

Lin J, Mu C, Wang Y, Li Z, Li X (2014). Physiological adaptive mechanisms of Leymus Chinensis during germination and early seedling stages under saline and alkaline conditions. Journal of Animal and Plant Sciences 24:904-912.

Lin JX, Li ZL, Wang YN, Mu CS (2014). Effects of various mixed saltalkaline stress conditions on seed germination and early seedling growth of Leymus chinensis from Songnen grassland of China. Notulae Botanicae Horti Agrobotanici Cluj-Napoca 42:154-159.

Lissner J, Schierup HH, Comin FA, Astorga V (1999). Effect of climate on the salt tolerance of two Phragmites australis populations: I. Growth, inorganic solutes, nitrogen relations and osmoregulation. Aquatic Botany 64:317-333.

Long X, Huang Z, Zhang Z, Li Q, Zed R, Liu Z (2010). Seawater stress differentially affects germination, growth, photosynthesis, and ion concentration in genotypes of Jerusalem artichoke (Helianthus tuberosus L.). Journal of Plant Growth Regulation 29(2):223-231.

Munns R(2002). Comparative physiology of salt and water stress. Plant Cell and Environment 25:239-250.

Parida AK, Das AB (2005). Salt tolerance and salinity effects on plants: a review. Ecotoxicology and Environmental Safety 60:324-349.

Peng YL, Gao ZW, Gao Y, Liu GF, Sheng LX, Wang DL (2008). Ecophysiological Characteristics of Alfalfa Seedlings in Response to Various Mixed Salt-alkaline Stresses. Journal of Integrative Plant Biology 50:29-39.
Saengthongpinit W, Sajjaanantakul T (2005). Influence of harvest time and storage temperature on characteristics of inulin from Jerusalem artichoke (Helianthus tuberosus L.) tubers. Postharvest Biology and Technology 37:93-100.

Shi DC, Wang DL (2005). Effects of various salt-alkali mixed stresses on Aneurolepidium chinense (Trin.) Kitag Plant and Soil 271:15-26.

Shi DC, Yin LJ (1993). Difference between salt $(\mathrm{NaCl})$ and alkaline $\left(\mathrm{Na}_{2} \mathrm{CO}_{3}\right)$ stresses on Puccinellia tenuiflora (Griseb.) Scribn. et Merr. Plants. Acta Botanica Sinica 35:144-149.

Tanji KK (1990). Nature and extent of agricultural salinity. In: Tanji KK (Ed), Agricultural Salinity Assessment and Management. New York, American Society of Civil Engineers pp 1-18.

Yang CW, ChongJ, Li C, Kim C, Shi DC, Wang DL (2007). Osmotic adjustment and ion balance traits of an alkali resistant halophyte Kochia sieversiana during adaptation to salt and alkali conditions. Plant and Soil 294:263-276.

Yang CW, Guo WQ, Shi DC (2010). Physiological roles of organic acids in alkali-tolerance of the alkali-tolerant halophyte chloris virgata. Agronomy Journal 4:1081-1089.

Yang CW, Shi DC, Wang DL (2008). Comparative effects of salt stress and alkali stress on growth, osmotic adjustment and ionic balance of an alkali-resistant halophyte Suaeda glauca (Bge.). Plant Growth Regulation 56:179-190.

Yang CW, Xu HH, Wang L, Liu J, Shi DC, Wang DL (2009). Comparative effects of salt-stress and alkali-stress on the growth, photosynthesis, solute accumulation, and ion balance of barley plants. Photosynthetica 47:79-86.

Yang JY, Zheng W, Tian Y, Wu Y, Zhou DW (2011). Effects of various mixed salt-alkaline stresses on growth, photosynthesis, and photosynthetic pigment concentrations of Medicago ruthenica seedlings. Photosynthetica 49:275-284.

Zhang JT, Mu CS (2009). Effects of saline and alkaline stresses on the germination, growth, photosynthesis, ionic balance and anti-oxidant system in an alkali-tolerant leguminous forage Lathyrus quinquenervius. Soil Science and Plant Nutrition 55:685-697.

Zhao GM, Liu ZP, Chen MD, Guo SW (2008). Soil properties and yield of Jerusalem artichoke (Helianthus tuberosus L.) with seawater irrigation in North China plain. Pedosphere 18:195-202.

Zhu GL, Deng XW, Zuo WN (1983). Determination of free proline in plants. Plant Physiology Communications 1:35-37.

Zhu JK (2003). Regulation of ion homeostasis under salt stress. Current Opinion in Plant Biology 6:441-445. 